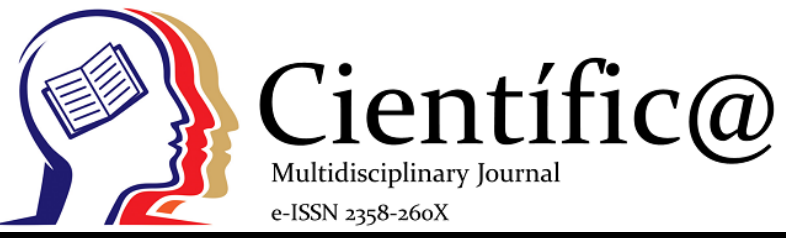

\title{
ANÁLISE DE CARBOIDRATOS SOLÚVEIS EM PLANTAS DE ARROZ
}

\author{
ANALYSIS OF SOLUBLE CARBOHYDRATES IN RICE PLANTS
}

\author{
Hélio Aparecido Matos Filho ${ }^{1}$, Renata de Castro Marques Carvalho ${ }^{2}$
}

\author{
${ }^{1}$ Autor para correspondência; Universidade Federal de Goiás - heliomatos1010@gmail.com \\ 2 Universidade Federal de Goiás
}

\section{Info}

Recebido: 12/2019

Publicado: 04/2020

DOI: $10.29247 / 2358-260 X .2020 v 7 i 1.4118$

ISSN: 2358-260X

Palavras-Chave
teor de amido, estresse hídrico, glicose,
frutose, sacarose
Keywords:
starch content, water stress, glucose,
fructose, sucrose

\section{Resumo}

Oryza Sativa L.é uma planta cujo fruto, arroz, é um prato típico do brasileiro, e adaptado ao cerrado brasileiro. A planta de arroz é rica em carboidratos. Neste trabalho foi analisado os teores de carboidratos solúveis totais em plantas de arroz da cultivar BRS Primavera submetidas ou não ao estresse hídrico e verificar se as plantas sob restrição hídrica apresentam maior teor de carboidratos solúveis nas folhas. Utilizou-se amostras secas de folhas de plantas de arroz da cultivar BRS Primavera, com as seguintes identificações (72.3: amostra sem condições de estresse hídrico; 83.1 e 83.3: amostras sob condições de estresse hídrico). Verificou-se que as plantas de arroz da cultivar BRS Primavera que estavam em condições de estresse hídrico apresentaram 119,87 e 81,36 mg de carboidratos por grama de matéria seca, nas amostras 83.3 e 83.1, respectivamente. Já as plantas que foram mantidas sob condições ótimas de umidade no solo apresentaram 49,45 mg. g -1 de carboidratos solúveis. 0 teor de amido nas folhas de arroz foi maior nas plantas mantidas em condições de estresse hídrico. As amostras 83.1 e 83.3 apresentaram 3.62 e $11.12 \mathrm{mg}$ de amido por grama de matéria seca a mais que a amostra 72.3 (sem restrição hídrica). Os resultados obtidos para o amido seguiram o mesmo comportamento dos resultados de glicose, frutose e sacarose, indicando que plantas de arroz cultivadas em condições de estresse hídrico tendem a aumentar o teor de carboidratos solúveis totais nas folhas como resposta de defesa às condições limitantes de umidade no solo. Conclui-se que plantas de arroz mantidas em condições de estresse hídrico apresentam maior teor de carboidratos não estruturais em suas folhas, quando comparadas às plantas cultivadas em condições ideais de água no solo. 


\section{INTRODUÇÃO}

A cultura do arroz (Oryza sativa L.) possui grande importância, pois é fonte primária de alimentação para mais de um terço da população mundial. Sua produção global em 2018 foi de 475,8 milhões de toneladas, o que corresponde por cerca de $22 \%$ da produção de grãos no cenário mundial (USDA, 2019). O Brasil participa com 12,43 milhões de $\operatorname{Mg}(2,17 \%$ da produção mundial) e destaca-se como único país não-asiático entre os 10 maiores produtores (CONAB, 2018). Apesar de sua importância, o setor sofre com a competitividade de outras culturas mais rentáveis, tais como a soja (Freitas \& Mendonça, 2016), milho (CONAB, 2019), além de restrições ambientais, principalmente em função da temperatura do ar (Santos \& Santiago, 2014) e irradiação solar (Heinemann, 2010) e déficit hídrico (Kadam, 2015).

A deficiência hídrica é a principal responsável pela baixa produtividade e instabilidade de produção do arroz de sequeiro. Os períodos de estiagem são caracterizados pela alta demanda evaporativa do ar, altos níveis de radiação solar e temperaturas elevadas (Steinmetz \& Meireles, 1999), podendo até causar a perda total da lavoura (Crusciol et al., 2003). A cultura do arroz apresenta sistema radicular superficial e alta exigência de água, sendo, portanto, pouco tolerante a períodos longos de deficiência hídrica (Wreger et al., 2001).

Alguns mecanismos morfofisiológicos podem estar relacionados com a tolerância à deficiência hídrica, tais como o uso moderado de água pela planta, habilidade de as raízes explorarem camadas mais profundas do solo, diminuição no volume das células, aumento na concentração do protoplasto, diminuição no tamanho das folhas, maior espessura e cerosidade da cutícula foliar, ângulo de inclinação da folha, além de acúmulo de compostos, como sacarose, frutose, amido, entre outros (Nguyen et al., 1997).
Estudos demonstram que plantas em condições de estresse hídrico tendem a aumentar os teores de carboidratos solúveis totais. Chaves Filho \& Seraphin (2001), verificaram que plantas de lobeira submetidas ao estresse hídrico ( $40 \%$ da capacidade de campo) tiveram aumento no teor de carboidratos solúveis totais de 17,96 mg. $\mathrm{g}^{-1}$ de MS nas folhas e $38 \mathrm{mg}$. $\mathrm{g}^{-1}$ de MS nas raízes comparadas ao tratado sem estresse hídrico. $\mathrm{O}$ aumento no teor de carboidratos solúveis totais foi observado por Irigoyen et al. (1992) em folhas de alfafa (Medicago sativa) como resposta ao estresse hídrico. Os teores de carboidratos solúveis totais foram de 90 mgg${ }^{1}$ de MS para um potencial hídrico de -1,5 MPa e de 170 mg. $\mathrm{g}^{-1}$ de MS para um. potencial hídrico de $-2,8 \mathrm{MPa}$ nas folhas. $\mathrm{O}$ objetivo deste trabalho foi analisar os teores de carboidratos solúveis totais em plantas de arroz da cultivar BRS Primavera submetidas ou não ao estresse hídrico.

\section{MATERIAL E MÉTODOS}

As análises de carboidratos solúveis foram feitas no Laboratório de Fisiologia Vegetal do Instituto de Ciências Biológicas da Universidade Federal de Goiás, durante a disciplina de Tópicos Especiais em Produção Vegetal. Utilizou-se amostras secas de folhas de plantas de arroz da cultivar BRS Primavera submetidas ou não ao estresse hídrico.

As amostras correspondiam às seguintes identificações:

1. 72.3: amostra seca de folhas de arroz da BRS Primavera sem condições de estresse hídrico (umidade do solo mantida na capacidade de campo);

2. 83.1 e 83.3: amostra seca de folhas de arroz da BRS Primavera sob condições de estresse hídrico. 
Método para extração e quantificação dos carboidratos solíveis nas folhas de arroz.

Para a extração e quantificação dos carboidratos nas folhas de arroz pesou-se $30 \mathrm{mg}$ de matéria seca de folha de arroz que foram armazenadas em tubo falcon e adicionou-se $3 \mathrm{ml}$ de etanol $80 \%$. As amostras foram agitadas manualmente, a fim de garantir a homogeneização. Em seguida, as amostras foram levadas ao banho maria por 15 minutos a uma temperatura de $80^{\circ} \mathrm{C}$. Após, foi realizada a centrifugação a $2500 \mathrm{rpm}$ por 10 minutos a $25^{\circ} \mathrm{C}$. O sobrenadante foi reunido em um tubo falcon de $15 \mathrm{ml}$. O procedimento foi repetido por mais quatro vezes, com o intuito de garantir a realização da extração exaustiva. O resíduo foi levado a estufa a uma temperatura de $50^{\circ} \mathrm{C}$ por 24 horas para posterior extração de amido. Ao fim deste procedimento tinhase um volume total de $15 \mathrm{ml}$ de extrato bruto etanólico. Adicionou-se ao extrato bruto clorofórmio $(10 \%$ do volume do extrato bruto) para realizar a purificação. $\mathrm{O}$ extrato foi levado para a centrífuga durante 10 minutos a uma rotação de $2500 \mathrm{rpm}$ para a separação de fases e eliminação dos constituintes apolares.

Para realizar a leitura das amostras no espectrofotômetro, utilizou-se $10 \mu \mathrm{l}$ da fração aquosa e $490 \mu \mathrm{l}$ de água deionizada, totalizando $500 \mu \mathrm{l}$ de amostra. Adicionou-se às amostras 2,5 $\mathrm{ml}$ de ácido sulfúrico e $500 \mu \mathrm{l}$ de fenol sulfúrico. Em seguida, realizou-se a leitura no espectrofotômetro a $490 \mathrm{~nm}$. Cada amostra foi feita em triplicata. Após a leitura, fezse os cálculos de carboidratos solúveis presentes nas amostras, com base na equação obtida na solução padrão (Eq. 1) $Y=0,0221 x+0,0329$, em que $\mathrm{Y}=$ Absorbância e x $=$ Concentração de Glicose

\section{Método para análise de açúcares neutros}

Para analisar os açúcares neutros e suas respectivas quantidades presentes nas amostras, utilizou-se $3 \mathrm{ml}$ de extrato que foram purificadas em uma coluna de troca iônica. Para isso, utilizaram-se seringas de $10 \mathrm{ml}$ preenchidas com resinas catiônicas e aniônicas. Colocou-se nas seringas um disco de lã de vidro, a fim de evitar a perda da resina. Após o preenchimento das colunas, a amostra foi aplicada primeiramente na seringa que contém resina na forma catiônica, localizada acima da seringa contendo resina aniônica. Colocaram-se as amostras dos extratos concentrados no topo das colunas e deu-se a eluição com água deionizada. Em seguida, verificou-se o $\mathrm{pH}$ das amostras, ajustando-o para uma faixa entre 6,9 e 7,2.

Após o ajuste do $\mathrm{pH}$, as amostras foram secas em evaporador rotativo, a uma temperatura de $40{ }^{\circ} \mathrm{C}$. Assim que se verificou que as amostras estavam secas, retirou-as do evaporador e procedeu-se a ressuspensão, utilizando $3 \mathrm{ml}$ de água ultrapura.

A partir da amostra ressuspendida, fez-se a análise qualitativa dos carboidratos, por meio da Cromatografia de Troca Aniônica de Alto Desempenho Acoplado à Detecção Eletroquímica Pulsada (HPAEC/PAD). Utilizou-se $1 \mathrm{ml} \mathrm{de} \mathrm{amostra} \mathrm{que} \mathrm{foi}$ filtrada, a fim de garantir maior grau de pureza. As amostras foram comparadas com a solução padrão contendo glicose, sacarose e frutose.

\section{Método para quantificação enzimática de amido}

A análise de amido presente na amostra foi feita a partir do resíduo sólido obtido após a extração exaustiva dos carboidratos solúveis totais. Pesou-se 10 $\mathrm{mg}$ de cada amostra e adicionou-se $0,4 \mathrm{ml}$ da enzima $\alpha$ amilase. Em seguida, fez-se a incubação do material por 30 minutos a $75^{\circ} \mathrm{C}$. As amostras foram resfriadas até atingir $\quad 50 \quad{ }^{\circ} \mathrm{C}$, acrescentando-se $\quad 0,4 \quad \mathrm{ml}$ de amoliglucosidase com posterior incubação por 30 minutos a $50{ }^{\circ} \mathrm{C}$. O procedimento foi repetido mais uma vez, totalizando $60 \mathrm{U} / \mathrm{ml}$. Após as incubações acrescentou-se $100 \mu$ de ácido perclórico e fez-se a 
centrifugação por 2 minutos. O precipitado formado foi descartado e o sobrenadante utilizado para a quantificação de amido.

Para a confecção da curva padrão utilizou-se alíquotas de $10 \mu \mathrm{l}$ de solução padrão de glicose $(100 \mathrm{ml}$. $\left.\mathrm{dL}^{-1}\right)$, nas concentrações de $0 ; 2,5 ; 5,0 ; 7,5 ; 10 \mu \mathrm{g} \mathrm{ml} \mathrm{m}^{-1}$. Adicionou-se $300 \mu \mathrm{l}$ de GOD/POD e fez-se a incubação em microplacas por $15 \mathrm{~min}$ a $37^{\circ} \mathrm{C}$. Depois da incubação o teor de glicose foi determinado em leitor de microplacas de ELISA em comprimento de onda $490 \mathrm{~nm}$.

\section{RESULTADOS E DISCUSSÃO}

O teor de carboidratos solúveis nas folhas de arroz foi maior nas plantas que estavam em condições de estresse hídrico (Tabela 1). Verificou-se que as plantas de arroz da cultivar BRS Primavera que estavam em condições de estresse hídrico apresentaram 119,87 e 81,36 mg de carboidratos por grama de matéria seca, nas amostras 83.3 e 83.1, respectivamente. Já as plantas que foram mantidas sob condições ótimas de umidade no solo apresentaram 49,45 mg. $\mathrm{g}^{-1}$ de carboidratos solúveis.

Tabela 1. Teor de carboidratos solúveis totais em folhas de arroz da cultivar BRS Primavera mantidas sem restrição hídrica e com restrição hídrica.

\begin{tabular}{lccc}
\hline \multirow{2}{*}{ Carboidratos } & $\mathbf{8 3 . 3}$ & $\mathbf{8 3 . 1}$ & $\mathbf{7 2 . 3}$ \\
\cline { 2 - 4 } & \multicolumn{2}{c}{ Com restrição hídrica } & Sem restrição hídrica \\
\hline Carb. Solúveis $\left(\mu \mathrm{g} \cdot \mu \mathrm{L}^{-1}\right)$ & 0,60739 & 0,440723 & 0,248899 \\
Açúcar no extrato $(\mathrm{mg})$ & 3,64434 & 2,64434 & 1,493396 \\
Matéria seca extrato $(\mathrm{g})$ & 0,0304 & 0,0325 & 0,0302 \\
$\mathrm{mg} \cdot \mathrm{g}^{-1} \mathrm{MS}$ & 119,8796 & 81,3643 & 49,45021 \\
\hline
\end{tabular}

Os resultados obtidos corroboram com Marur (1998) em plantas de Gossypium birsutum L. sob condições de estresse hídrico. $\mathrm{O}$ autor verificou que o teor de amido e os níveis de açúcares redutores aumentaram significativamente nas plantas submetidas ao estresse hídrico. Charles Filho \& Seraphin (2001), também verificaram o mesmo comportamento em plantas de Solanum lycocarpum com restrição hídrica. O teor de carboidratos solúveis teve aumento de 17,96 mg. $g^{-1}$ de MS nas plantas sob estresse hídrico. Segundo Kramer (1995), a seca exerce importante influência no teor de carboidratos em diversas espécies. Em virtude do efeito da seca o amido é degradado nos tecidos que o acumulam. A redução na quantidade de amido é uma consequência da atividade da amilase, sendo acompanhada por um aumento da quantidade de açúcares solúveis redutores. $\mathrm{Na}$ maioria das plantas, a sacarose é o principal açúcar exportado dos locais de síntese (folhas) para as regiões de consumo (caule, raízes, raízes e órgãos reprodutivos) onde será utilizada para o crescimento e/ou armazenamento. As hexoses liberadas a partir da hidrólise de sacarose podem ser utilizadas em processos anabólicos e catabólicos e também fornecendo açúcares redutores para o processo de ajustamento osmótico. Dentre as enzimas que participam dessa hidrólise, as invertases parecem ser mais ativas do que a sacarose sintase (Kingston-Smith et al., 1999).

Segundo Zhonng et al. (2018), as atividades de glutamato desidrogenase, transaminase glutâmicooxalacética e transaminase glutâmico-pirúvica são aumentadas em condições de menor disponibilidade de água no solo. Como consequência, os aminoácidos e o açúcar solúvel são significativamente aumentados. Os açúcares podem agir como protetores osmóticos durante a desidratação celular causada por estresses abióticos, tal como o estresse hídrico. Os açúcares induzem as atividades de outros componentes do 
sistema antioxidante de uma planta. Nos últimos anos, estudos tem mostrado que os açúcares também têm sido caracterizados por sua via de sinalização, que modula a expressão de importantes genes que fornecem tolerância ao estresse abiótico para a planta (Gangola \& Ramadoss, 2018).

Os perfis cromatográficos dos carboidratos solúveis das folhas de amostras estão representados nas

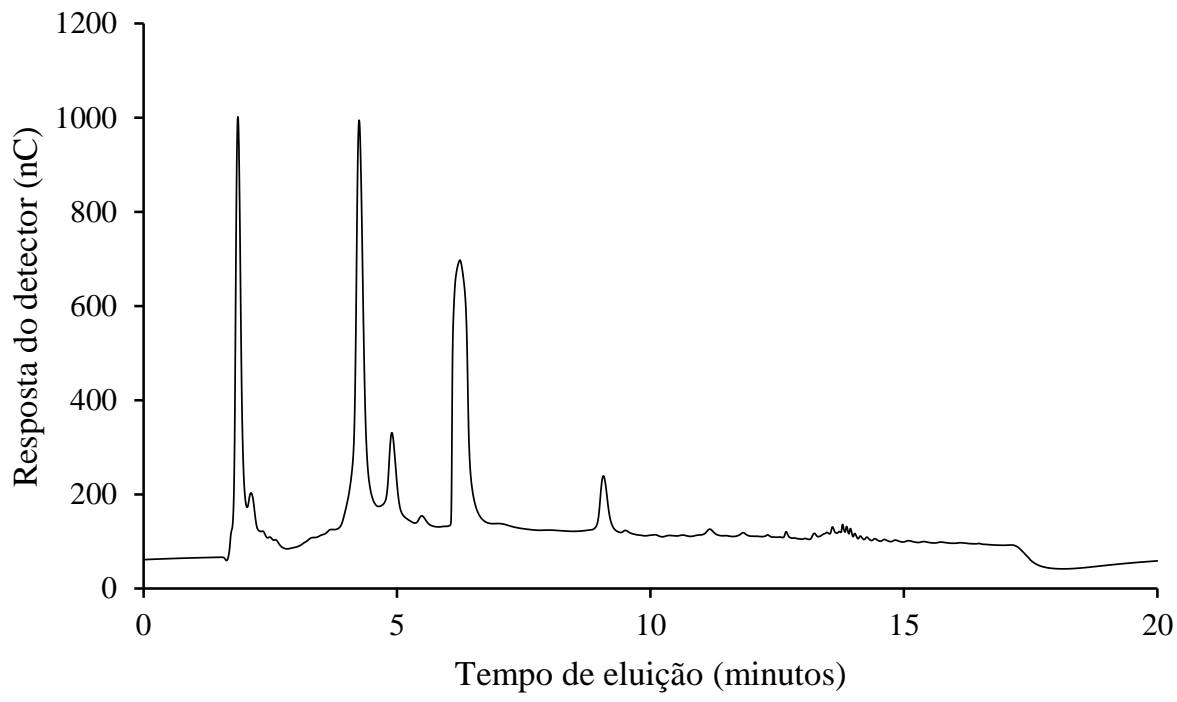

Figura 1. Perfil de carboidratos solúveis por HPAEC/PAD em folhas de plantas de arroz da BRS Primavera sem estresse hídrico (Amostra 72.3) (G) glicose, (F) frutose, (S) sacarose. Amostra 72.3.

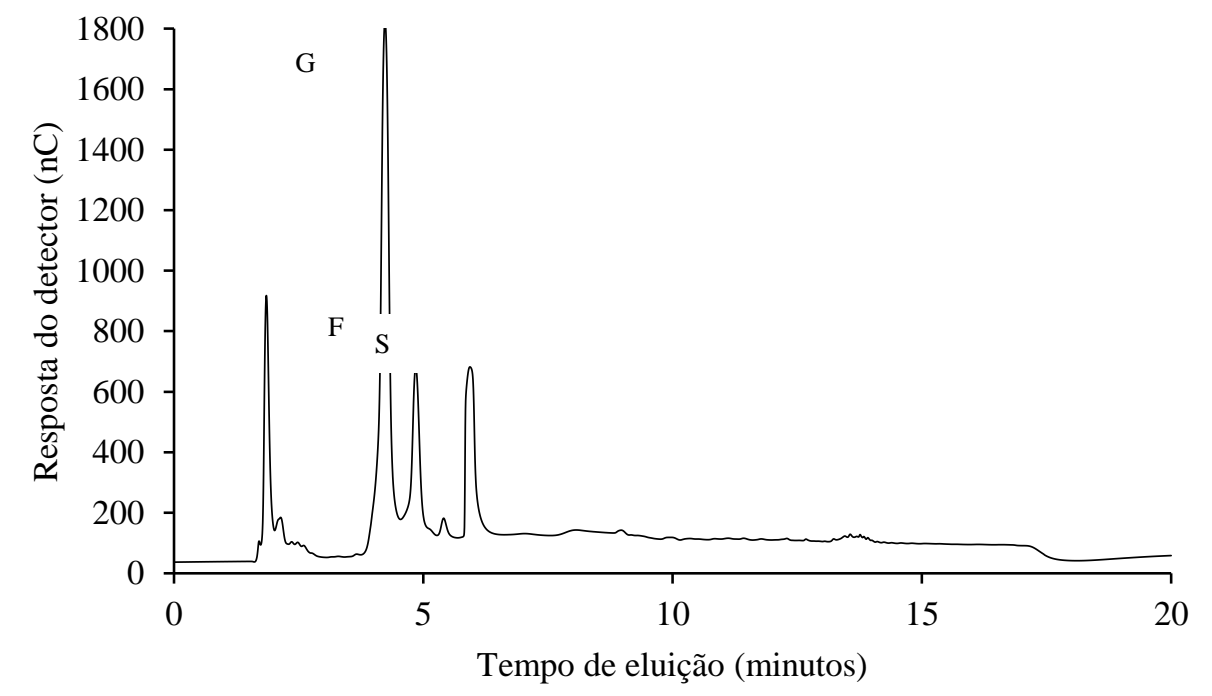

Figura 2. Perfil de carboidratos solúveis por HPAEC/PAD em folhas de plantas de arroz da BRS Primavera sob estresse hídrico (Amostra 83.1). (G) glicose, (F) frutose, (S) sacarose. figuras 1, 2 e 3. Em todas foram identificadas glicose, sacarose e frutose. As amostras 8 G 83.3 submetidas a restrição hídrica apresentaram picos de retenção e condutividade semelhantes quando comparadas à amostra 72.3 (sem restrição hídrica) (Figuras 1, 2 e 3, respectivamente). Os picos correspondem à glicose; frutose e sacarose, respectivamente. 


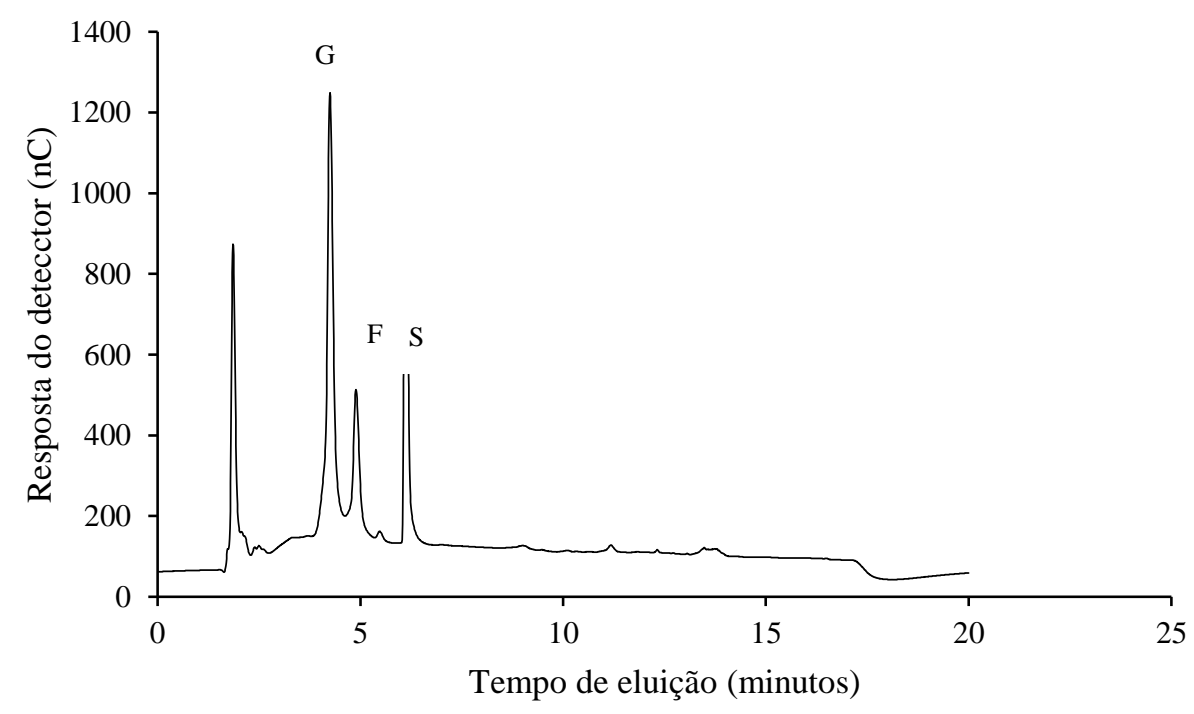

Figura 3. Perfil de carboidratos solúveis por HPAEC/PAD em folhas de plantas de arroz da BRS Primavera sob estresse hídrico (Amostra 83.3). (G) glicose, (F) frutose, (S) sacarose.

Verificou-se que plantas de arroz mantidas em condições ótimas de água no solo, apresentaram menor teor de carboidratos totais (89.33), quando comparadas às plantas mantidas em condições limitantes de umidade no solo (138.39 e 121.34, para as amostras 83.1 e 83.3, respectivamente (Tabela 2).

Os açúcares, álcoois de açúcar e amido são os principais componentes do pool de carbono móvel nas plantas. $\mathrm{O}$ estresse hídrico afeta substancialmente o balanço de carbono nas plantas, bem como as reservas de carbono móvel, podendo levar à sua exaustão e ao desenvolvimento de carência de carbono. Além de sua função como compostos de reserva, muitos açúcares e álcoois de açúcar desempenham funções específicas de proteção sob estresse hídrico, atuando como compostos osmoticamente ativo. Pode-se supor que a rafinose (polímeros naturais de frutose que usualmente são encontrados ligados a uma molécula inicial de glicose) e os álcoois de açúcar não cíclicos desempenham um papel na resposta de muitas espécies ao estresse hídrico (Ivanov et al., 2019).

Tabela 2. Carboidratos solúveis (Sacarose, Frutose e Glicose) presentes em folhas de plantas de arroz da cultivar BRS Primavera sem e com restrição hídrica, obtidas por HPAEC/PAD.

\begin{tabular}{lcccc}
\hline \multirow{2}{*}{ Amostras } & \multicolumn{4}{c}{ Carboidratos $(\boldsymbol{\mu g} / \mathbf{m l})$} \\
\cline { 2 - 5 } Sem restrição hídrica (72.3) & Sacarose & Frutose & Glicose & Total \\
Com restrição hídrica (83.1) & 43.36 & 13.84 & 32.13 & 89.33 \\
Com restrição hídrica (83.3) & 61.62 & 21.80 & 54.97 & 138.39 \\
\hline
\end{tabular}

O teor de amido nas folhas de arroz foi maior nas plantas mantidas em condições de estresse hídrico (Tabela 3). As amostras 83.1 e 83.3 apresentaram 3.62 e $11.12 \mathrm{mg}$ de amido por grama de matéria seca a mais que a amostra 72.3 (sem restrição hídrica). Os resultados obtidos para o amido seguiram o mesmo comportamento dos resultados de glicose, frutose e sacarose, indicando que plantas de arroz cultivadas em condições de estresse hídrico tendem a aumentar o teor de carboidratos solúveis totais nas folhas como resposta de defesa às condições limitantes de umidade no solo. Segundo Tretheway \& Smith (2000), o amido é o carboidrato de reserva mais abundante nas plantas em termos quantitativos. É constituído por diferentes 
polímeros de glicose arranjados em uma estrutura semicristalina tridimensional dando origem a um grânulo.

O amido é depositado na forma de grânulos e ocorre em quase todas as plantas, em vários tipos de tecidos e órgãos como folhas, raízes, caules, frutos e sementes. Nas folhas, seu acúmulo é devido à fixação de carbono durante a fotossíntese e este amido formado na luz é degradado no escuro dando origem a produtos

que são utilizados, na maioria dos casos, na síntese de sacarose. Este amido estocado nos cloroplastos é comumente conhecido como amido transitório. A sacarose formada nas folhas é transportada pelos tecidos vasculares para outros órgãos, atuando como fonte de energia para o crescimento ou, então, é estocada na forma de polissacarídeos de reserva (Preiss, 2004).

Tabela 3. Teor de amido em folhas de arroz da cultivar BRS Primavera mantidas sem restrição hídrica e com restrição hídrica.

\begin{tabular}{lccc}
\hline \multirow{2}{*}{ Amido } & $\mathbf{8 3 . 1}$ & $\mathbf{8 3 . 3}$ & $\mathbf{7 2 . 3}$ \\
\cline { 2 - 4 } & \multicolumn{1}{c}{ Com restrição hídrica } & Sem restrição hídrica \\
\hline$\mu \mathrm{g} . \mu \mathrm{L}^{-1}$ de amido & 0.27 & 0.42 & 0.19 \\
Amido total no extrato $(\mu \mathrm{g})$. & 415.39 & 615.01 & 299.88 \\
mg de amido por g de MS & 13.71 & 21.21 & 10.09 \\
\hline
\end{tabular}

As plantas de arroz (Oryza sativa L.) frequentemente alteram as características morfoanatômicas, processos fisiológicos e bioquímicos, redes de expressão e regulação metabólica em resposta à condição de estresse hídrico (Kathiresan et al., 2006; Ji et al., 2012). Em condições de estresse hídrico as plantas tendem a aumentar o teor de carboidratos não estruturais nas folhas, caules e raízes, como resposta de defesa e mecanismo de tolerância à deficiência de água (Rich \& Watt, 2013).

\section{CONCLUSÃO}

Plantas de arroz mantidas em condições de estresse hídrico apresentam maior teor de carboidratos não estruturais em suas folhas, quando comparadas às plantas cultivadas em condições ideais de água no solo.

\section{REFERÊNCIAS BIBLIOGRÁFICAS}

CONAB. COMPANHIA NACIONAL DE ABASTECIMENTO. Boletim da safra de Grãos. Safra 2018/19. Disponível em:< https://www.conab.gov.br/info- agro/safras/graos/boletim-da-safra-de-graos $>$. Acesso em 03 set. 2019.

CONAB. COMPANHIA NACIONAL DE ABASTECIMENTO. Acompanhamento da Safra Brasileira de Grãos. Safra 2017/18, v. 5, n.7: Conab, 2018.

CHAVES FILHO, J. T.; SERAPHIN, E. S. Alteração no potencial osmótico e teor de carboidratos solúveis em plantas jovens de lobeira (Solanum lycocarpum St.-Hill.) em resposta ao estresse hídrico. Revista Brasileira de Botânica, v. 24, n. 2, 0. $199-204,2001$.

CRUSCIOL, C. A. C.; ARF, O.; SORATTO, R. P.; MACHADO, J. R. Influência de lâminas de água e adubação mineral na nutrição e produtividade de arroz de terras altas. Revista Brasileira de Ciência do Solo, v. 27, p. 647-654, 2003.

GANGOLA, M. P.; RAMADOSS, B. R. Sugars desempenham um papel crítico na tolerância ao estresse abiótico em plantas. Em: Avenidas Bioquímicas, Fisiológicas e Moleculares no Combate à Tolerância ao Estresse Abiótico em Plantas. Academic Press, 2018. p. 17-38.

HEINEMANN, A.B. Caracterização dos padrões de estresse hídrico para a cultura do arroz (ciclo curto e médio) no estado de Goiás e suas consequências para o melhoramento 
genético. Ciência e Agrotecnologia, v. 34, n. 1, p. 29 - 36, 2010.

IVANOV, Y. V., KARTASHOV, A. V., ZLOBIN, I. E., SARVIN, B., STAVRIANIDI, A. N., \& KUZNETSOV, V. V. Water deficit-dependent changes in non-structural carbohydrate profiles, growth and mortality of pine and spruce seedlings in hydroculture. Environmental and experimental Botany, v. 157, p. $151-160$, 2019.

IRIGOYEN, J.J., EMERICH, D.W. \& SÁNCHEZDÍAZ, M. Water stress induced changes in concentrations of proline and total soluble sugars in nodulated alfalfa (Medicago sativa) plants. Physiolgia Plantarum 84:55-60, 1992.

JI, K. X.; WANG, Y. Y.; SUN, W. N.; LOU, Q. J.; MEI, H. W.; SHEN, S. H.; CHEN, H. Droughtresponsive mechanisms in rice genotypes withcontrasting drought tolerance during reproductive stage. Journal Plant Physiology, v. 169 , p. $336-344,2012$.

KADAM, NN, YIN, X., BINDRABAN, PS, STRUIK, PC E JAGADISH, KS. A plasticidade morfológica e anatômica durante o estádio vegetativo torna o trigo mais tolerante ao estresse hídrico que o arroz. Revista Brasileira de Fisiologia Vegetal, v. 167, n. 4, p. 13891401, 2015.

KATHIRESAN A, LAFITTE H. R, CHEN J. X, MANSUETO L, BRUSKIEWICH, R, BENNETT, J. Gene expression microarrays and their application in drought stress research. Field Crop Research, v. 97, p. $102-110,2006$.

KRAMER, P. J. Water relations of plants and soils. Academic Press, London, 1995.

MARUR, C. J. Fotossíntese e translocação de carboidratos em algodoeiros submetidos a déficit hídrico após a aplicação de cloreto de mepiquat. Revista Brasileira de Fisiologia Vegetal, v. 10, p. $59-64,1998$.

NGUYEN, H. T.; BABU, R. C.; BLUM, A. Breeding for drought resistance in rice: physiology and molecular genetics considerations. Crop Science, v. 37, n. 5, p. 1426-1437, 1997.

PREISS, J. Plant starch synthesis. In: Eliasson, A. C. (Ed.). Starch in food-structure, function and apllications. Boston: New Yorj; Washington: CRC Press, 2004. p. 3 - 49.

RICH, S. M.; WATT, M. Soil conditions and cereal root system architecture: review and considerations for linking Darwin and Weaver. Journal Experimental Botany, v. 64, p. 1193 1208, 2013.

SANTOS, A. B.; SANTIAGO, C. M. Informações técnicas para a cultura do arroz irrigado nas regiões norte e nordeste do Brasil. Embrapa Arroz e Feijão. Santo Antônio de Goiás, 2014.

STEINMETZ, S.; MEIRELES, E.J.L. Clima. In: VIEIRA, N. R.A. A cultura do arroz no Brasil. Santo Antônio de Goiás: Embrapa Arroz e Feijão, 1999. cap.3, p.58-87.

UNITED STATES DEPARTMENT OF AGRICULTURE. Rice outlook:2018. Disponível em: $<$

https://www.ers.usda.gov/publications/pubdetails/?pubid=92852>. Acesso em 03 set. 2019.

TRETHEWAY, R.; SMITH, A. M. Starch metabolism in leaves. In: LEEGOOD, R. C.; SHARKEY, T.; VON CAEMMERER, S. Photosynthesis: Phisiology and Metabolism. Kluwer Academic Publishers, 2000. p. 205 - 231.

ZHONG, C., CAO, X., BAI, Z., ZHANG, J., ZHU, L., HUANG, J., \& JIN, Q. O metabolismo do nitrogênio se correlaciona com a aclimatação da fotossíntese ao estresse hídrico de curto prazo no arroz (Oryza sativa L.). Fisiologia vegetal e Bioquímica, v. 125, p. 52-62, 2018.

WREGER, M.S.; CARAMORI, P. H.; GONÇALVES, S. L.; COLASANTE, L. O.; FUKOSHIMA, M. T.; ABUD, N. S. Determinação das melhores épocas de semeadura do arroz de sequeiro, Oryza sativa, no Estado do Paraná. Acta Scientiarum, v.23, n.5, p.1179-1183, 2001. 